\title{
Linear Regression to Approximate Longitudinal Growth Curves: Revised Standards for Velocity of Weight and Length in Infants
}

\author{
HERBERT H. POMERANCE ${ }^{(12)}$ AND JOHN M. KRALL \\ Department of Pediatrics, Charleston Division, West Virginia University Medical Center, Charleston, West Virginia \\ [H.H.P.], and Department of Community Medicine, West Virginia University Medical Center, \\ Morgantown, West Virginia, USA [J. M. K.]
}

\section{Summary}

Because of lack of acceptability of the previous log-linear model of slope velocity for the assessment of weight and length in children 1 to 36 months of age, a modified method for least squares determination of velocity of growth by slope has been designed. This model uses a compound logarithmic expression of time and a newly designed graphic scale. The acceptability of the graphic (hand-drawn) line is retained while "goodness of fit" of the model is improved. This improved model makes it possible to revise our standards for velocity of growth of children 1 to 36 months of age.

\section{Speculation}

When applied to clinical situations of abnormal growth, this model shouldhelp in the evaluation of patient growth. Along with the previously developed model for children 3 to $12 \mathrm{yr}$ of age, it will form the basis for new office charts for the practitioner.
Physicians have used tables and charts for assessment of growth for many years. The earliest techniques were cross-sectional. Their development was stimulated primarily by a pressing need: crosssectional studies could be prepared rapidly. The landmark work of Vickers and Stuart (10), leading to the long-used "Stuart charts"; the Iowa study by Meredith (4); and the more recently published information and charts from the National Center for Health Statistics (6) are all evidences of need being met.

A recent publication by Pomerance (7), however, reaffirmed that cross-sectional data and its charts have an intrinsic weakness in that they require a comparison of the measurements obtained for one child, longitudinally over a period of time, with standards obtained by measuring different children at each of the measurement points. This may not truly be valid. Thus, after the initial need was met, attempts were made to use longitudinal data for creation of standards. Such data would allow the determination of rate (velocity) of growth for comparison of the individual

TYPICAL GROWTH CURVE FOR WEIGHT OF INFANT BOY

GRAPHIC VS LEAST SQUARES LINE

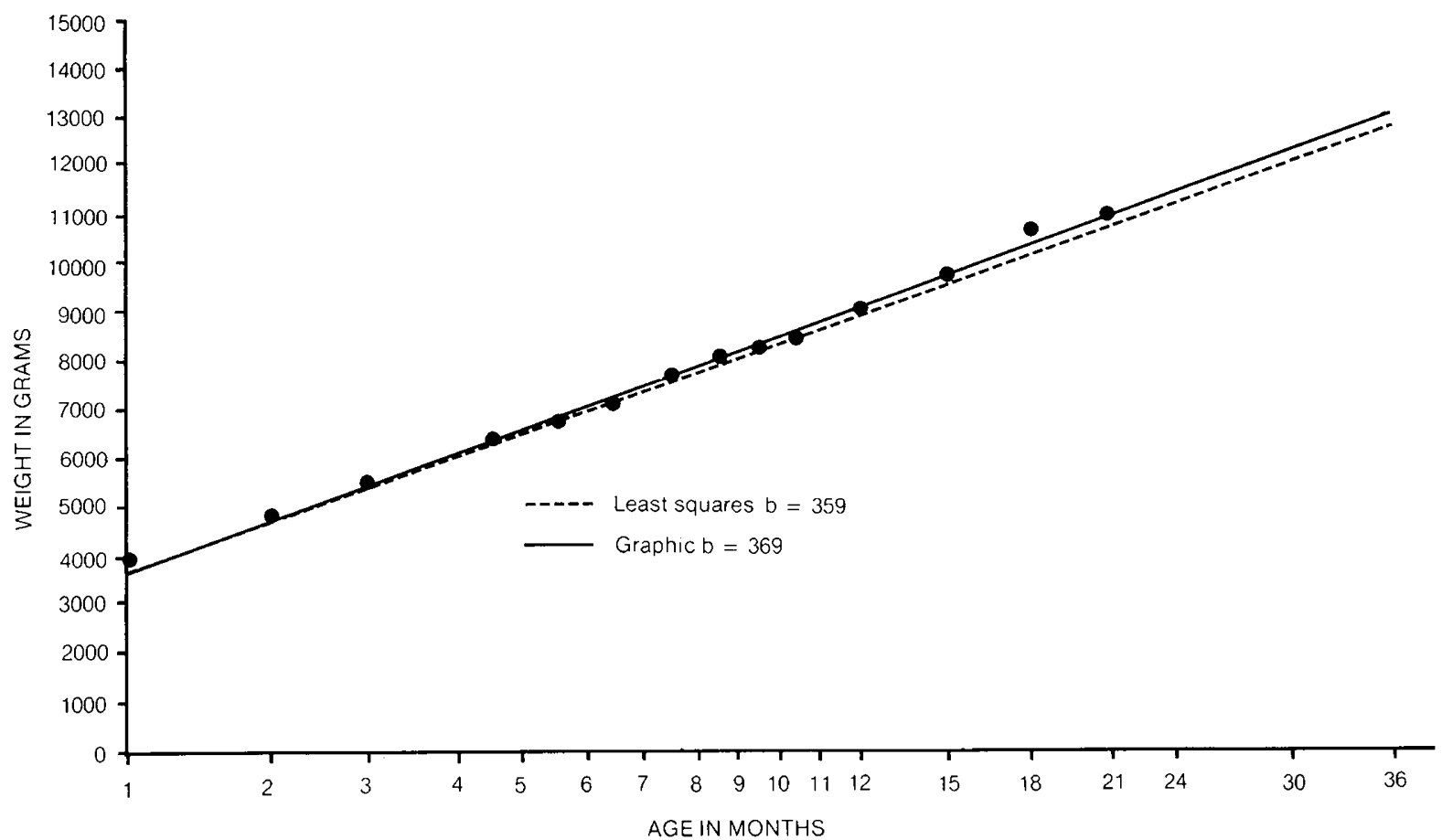

Fig. 1. A typical growth curve for weight of an infant boy. Weight is plotted against a special compound logarithmic scale of time. The closeness of slopes of both the calculated (least squares) line and the graphic (hand-drawn) line is apparent. 
TYPICAL GROWTH CURVE (LEAST SQUARES LINE) FOR LENGTH OF INFANT BOY WITH INSIGNIFICANT RUNS TEST

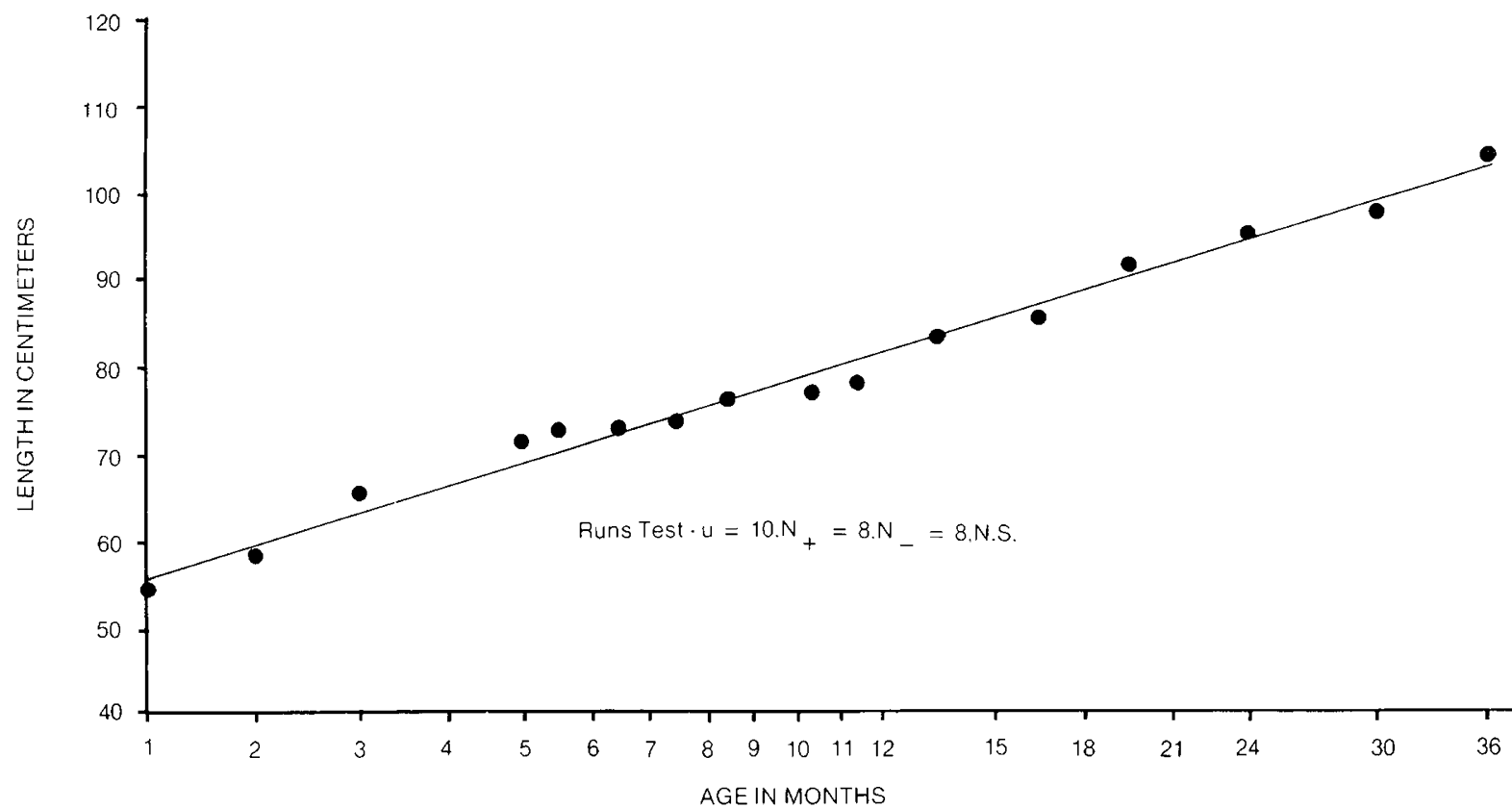

Fig. 2. A typical growth curve for length of an infant boy. The improved scale produces a least squares line which is nearly accurate, with an insignificant runs test ( 10 groups of data points on opposite sides of the line, eight positive and eight negative points).

Table 1. Runs tests for goodness of fit and coefficients of determination, compound logarithmic model

\begin{tabular}{|c|c|c|c|}
\hline Group & $\begin{array}{c}\text { Sample } \\
\text { size } \\
(N)\end{array}$ & $\begin{array}{l}\text { No. with } \\
\text { significant } \\
\text { runs test } \\
\text { at } 0.10 \\
\text { level }\end{array}$ & $\begin{array}{l}\text { No, with } \\
r^{2} \geq 0.90 \\
\end{array}$ \\
\hline $\mathrm{Wt}$-infant boys & 50 & 21 & 50 \\
\hline Wt-infant boys & 50 & 17 & 50 \\
\hline Length-infant boys & 50 & 14 & 50 \\
\hline Length-infant girls & 50 & 10 & 50 \\
\hline
\end{tabular}

Table 2. Spearman rank correlations for growth velocities, all infants 1 to 36 months of age, log versus compound log scale

\begin{tabular}{lcc}
\hline & $\begin{array}{c}\text { Scale (r: Log vs } \\
\text { compound log) }\end{array}$ & No. of infants \\
\hline Wt-infant boys & +0.86 & 1737 \\
Wt-infant girls & +0.90 & 1565 \\
Length-infant boys & +0.50 & 1731 \\
Length-infant girls & +0.62 & 1563 \\
\hline
\end{tabular}

${ }^{1}$ Interpretation: $+1=$ perfect agreement; $-1=$ perfect disagreement; 0 $=$ no agreement.

patient with established longitudinal norms. A different but big problem was found. Our own study (7) of 3995 children over a 20-year period demonstrated that, although standards could be developed for interval velocity (the rate of change from one measurement point to another), such standards were totally dependent upon measurement at very specific age points. Tanner $e t$ al.'s work $(8,9)$ recognized this problem and avoided it by annualizing all rates. This, however, reduced the practicability of the method by making interval changes less easy to observe.
To remove this objection, techniques have been reported which reduce the recording of growth to a straight line. Most such attempts have used cumbersome mathematical conversions which are not practicable for the clinician. Prerequisites for such a method must be accuracy and ease of application by the health professional. One reasonable model was reported by Wingerd (11) in 1970.

We postulated that, although growth lacks true linearity, this can be compensated, where necessary, by the use of logarithmic expessions of time. A new approach was developed which plotted all data for each patient individually using a linear scale for time for children ( 3 to 12 years) and a logarithmic scale for time for infants ( 1 to 36 months) (7). Straight lines were fitted to each patient's data by the least squares method, and in almost all instances, a coefficient of determination $\left(\mathrm{r}^{2}\right)$ of $\geq 0.90$ was achieved. Thus, the slopes of these lines appeared to provide a valuable measure of velocity of growth. Rankings of these slopes provided distributions of velocities of growth, freed from dependence upon specific age intervals. Tabular and graphic presentations provided a longitudinal model against which growth in an individual infant or child might be assessed. Applications were provided for both tabular and graphic methods.

As a follow-up to the development of this technique, an analysis of errors of calculated and hand-drawn lines and of the fit of the time scales was performed. Random samples of 50 records in each of the eight groups were studied: weight and length in infant boys and infant girls, and weight and height in boys and girls (3). It was found that the hand-drawn straight line fit of a growth curve by the health professional coincides well with the use of a least squares formula, that a linear time scale for children (3 to 12 years) in a growth curve produces good fit with practically no curvilinearity (i.e., growth in this period of time is almost linear), and that the method for linearizing growth curves in infants ( 1 to 36 months) by using a simple logarithmic scale for time, although producing high coefficients of determination $\left(r^{2} \geq 0.90\right)$ lacks sufficient accuracy for adoption by physicians for prospective use.

This paper reports further development of the model for infants in order to improve the fit. 


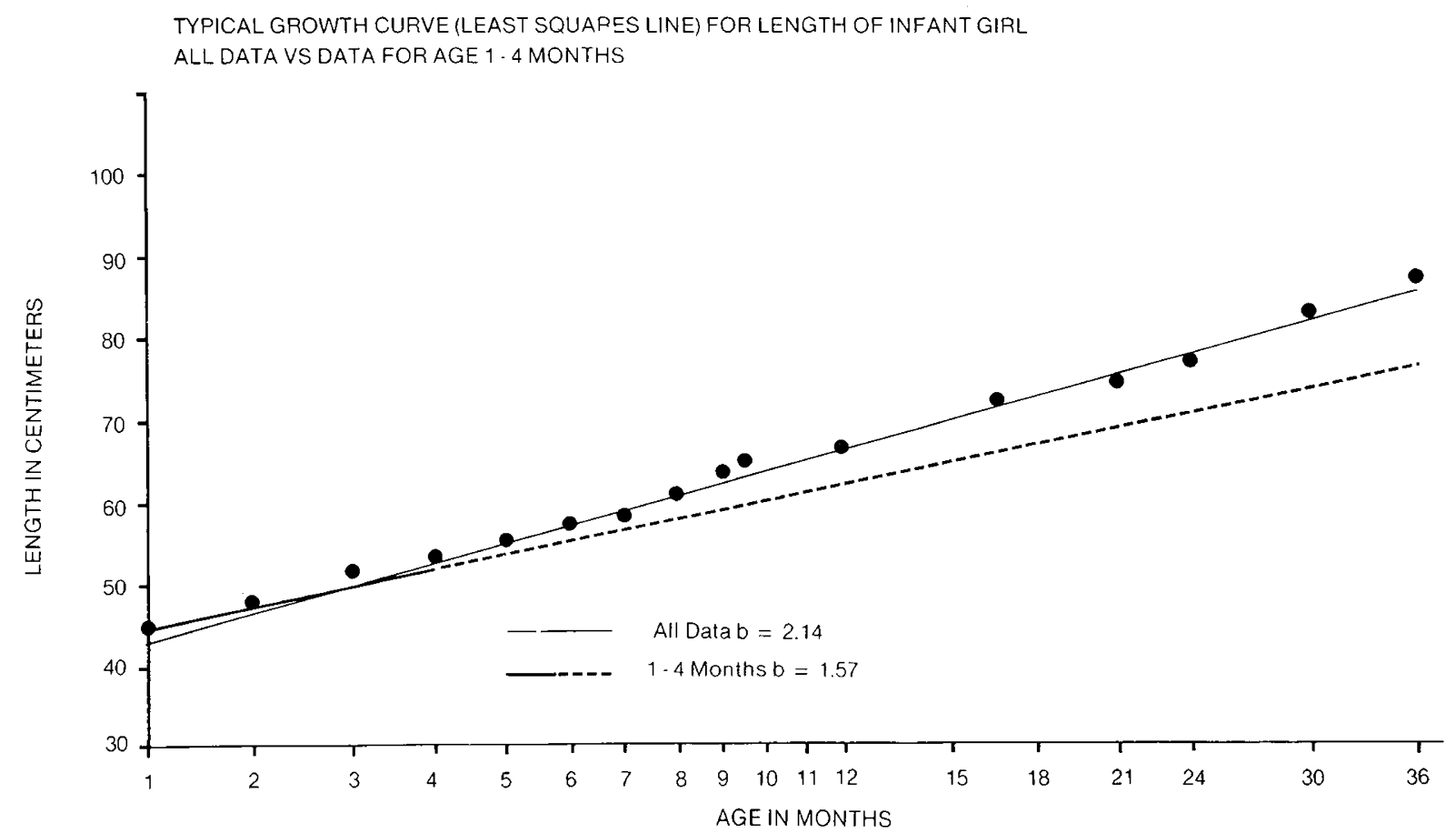

Fig. 3. A typical growth curve for length of an infant girl. Note the cifference between slopes when all data are plotted and when only the earliest data are used; the difference was reduced from $58 \%$ when using a log scale to $25 \%$ with the new scale.

Table 3. Velocities (slopes) of infant growth, all data for 1 to 4 months

\begin{tabular}{|c|c|c|c|c|c|}
\hline Group & $a^{1}$ & $\begin{array}{c}\text { Sample size }{ }^{2} \\
(N)\end{array}$ & $\begin{array}{l}\text { (1) } \\
\text { Ave. slopes } \\
\text { all data }\end{array}$ & $\begin{array}{l}\text { (2) } \\
\text { Ave. slopes } \\
1-4 \text { mos. }\end{array}$ & 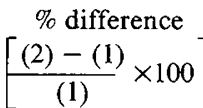 \\
\hline Wt-infant boys & 3.47 & 31 & 443 & 457 & $+3.2 \%$ \\
\hline Length-infant boys & 1.78 & 30 & 2.28 & 2.36 & $+3.5 \%$ \\
\hline Length-infant girls & 1.78 & 26 & 2.13 & 2.13 & $0.0 \%$ \\
\hline
\end{tabular}

${ }^{1}$ Constant used in compound logarithmic expression of time.

${ }^{2}$ Comparison made only for those subjects who had visits recorded each month for the first 4 months.

Table 4. Slopes of weight of infant boys and girls ages 1 to 36

\begin{tabular}{lcc}
\multicolumn{3}{c}{ months } \\
\hline Slope (velocity) & $\begin{array}{c}\text { Infant boys } \\
(\mathrm{g} / \text { compound } \\
\log \text { mo. })^{1}\end{array}$ & $\begin{array}{c}\text { Infant girls } \\
(\mathrm{g} / \text { compound } \\
\log \text { mo. })^{1}\end{array}$ \\
\hline Highest & 743.3 & 734.9 \\
95th percentile & 547.7 & 524.7 \\
90th percentile & 510.0 & 493.7 \\
75th percentile & 459.7 & 442.6 \\
50th percentile & 410.3 & 394.0 \\
25th percentile & 365.3 & 347.4 \\
10th percentile & 325.7 & 310.4 \\
5th percentile & 309.6 & 294.9 \\
Lowest & 253.7 & 197.5 \\
& & \\
No. of observations & 1737 & 1568 \\
No. with $\mathrm{r}^{2} \geq 0.9$ & 1726 & 1554 \\
\hline
\end{tabular}

${ }^{1}$ Months $=1 \mathrm{n}^{2}(\mathrm{x})+3.47 \ln (\mathrm{x})$

\section{MATERIALS AND METHODS}

A parabolic curve was developed in the form:

$$
y=a+b \ln (x)+c \ln ^{2}(x)
$$

where $y$ represents weight (or length), $x$ is age in months, and $1 n$ is the natural logarithm. Via the least squares method (5), this curve was fitted to the median points of weight (or length) of boys and girls, using the Pomerance (7) data for infants. The curves
Table 5. Slopes of length of infant boys and girls ages 1 to 36

\begin{tabular}{lcc}
\multicolumn{3}{c}{ months } \\
\hline \multicolumn{1}{c}{ Slope (velocity) } & $\begin{array}{c}\text { Infant boys } \\
(\mathrm{cm} / \text { compound } \\
\log \text { mo.* })^{1}\end{array}$ & $\begin{array}{c}\text { Infant girls } \\
(\mathrm{cm} / \text { compound } \\
\text { log mo. })^{1}\end{array}$ \\
\hline Highest & 3.76 & 3.36 \\
95th Percentile & 2.55 & 2.48 \\
90th Percentile & 2.44 & 2.40 \\
75th Percentile & 2.30 & 2.28 \\
50th Percentile & 2.17 & 2.14 \\
25th Percentile & 2.04 & 2.01 \\
10th Percentile & 1.92 & 1.88 \\
5th Percentile & 1.86 & 1.81 \\
Lowest & 1.42 & 1.44 \\
& & 1567 \\
No. of observations & 1735 & 1560 \\
No. with $\mathrm{r}^{2} \geq 0.9$ & 1728 & \\
\hline
\end{tabular}

${ }^{1}$ Months $=1 \ln ^{2}(\mathrm{x})+1.78 \ln (\mathrm{x})$.

were:

$$
y=141.41+48.90 \ln (x)+14.11 \ln ^{2}(x)
$$

for weights, and

$$
y=21.51+1.51 \ln (x)+0.85 \ln ^{2}(x)
$$

for lengths. 


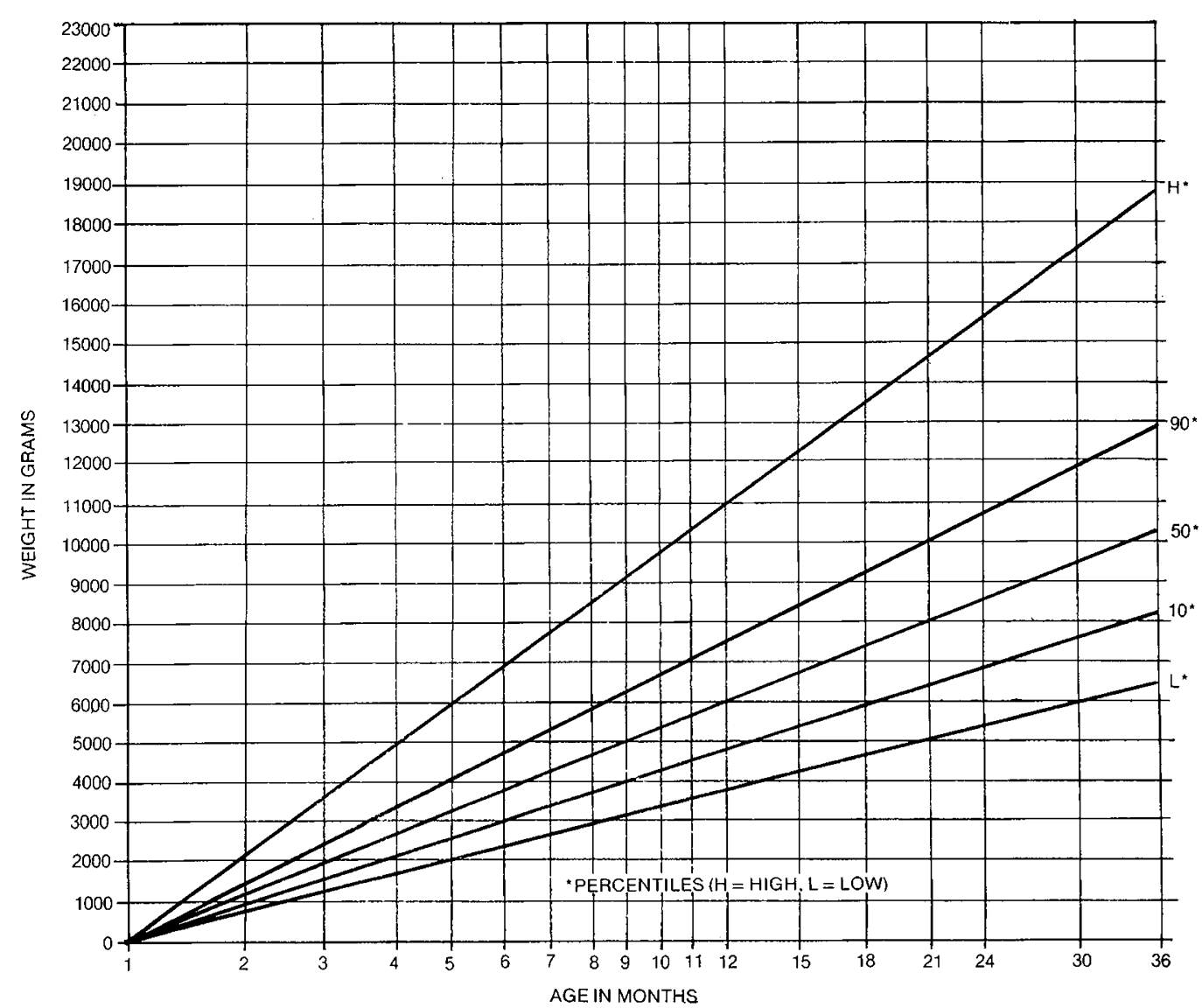

Fig. 4. Percentiles of slope velocity of weight for infant boys, from 1 to 36 months, including highest and lowest values of slope (compound logarithmic model).

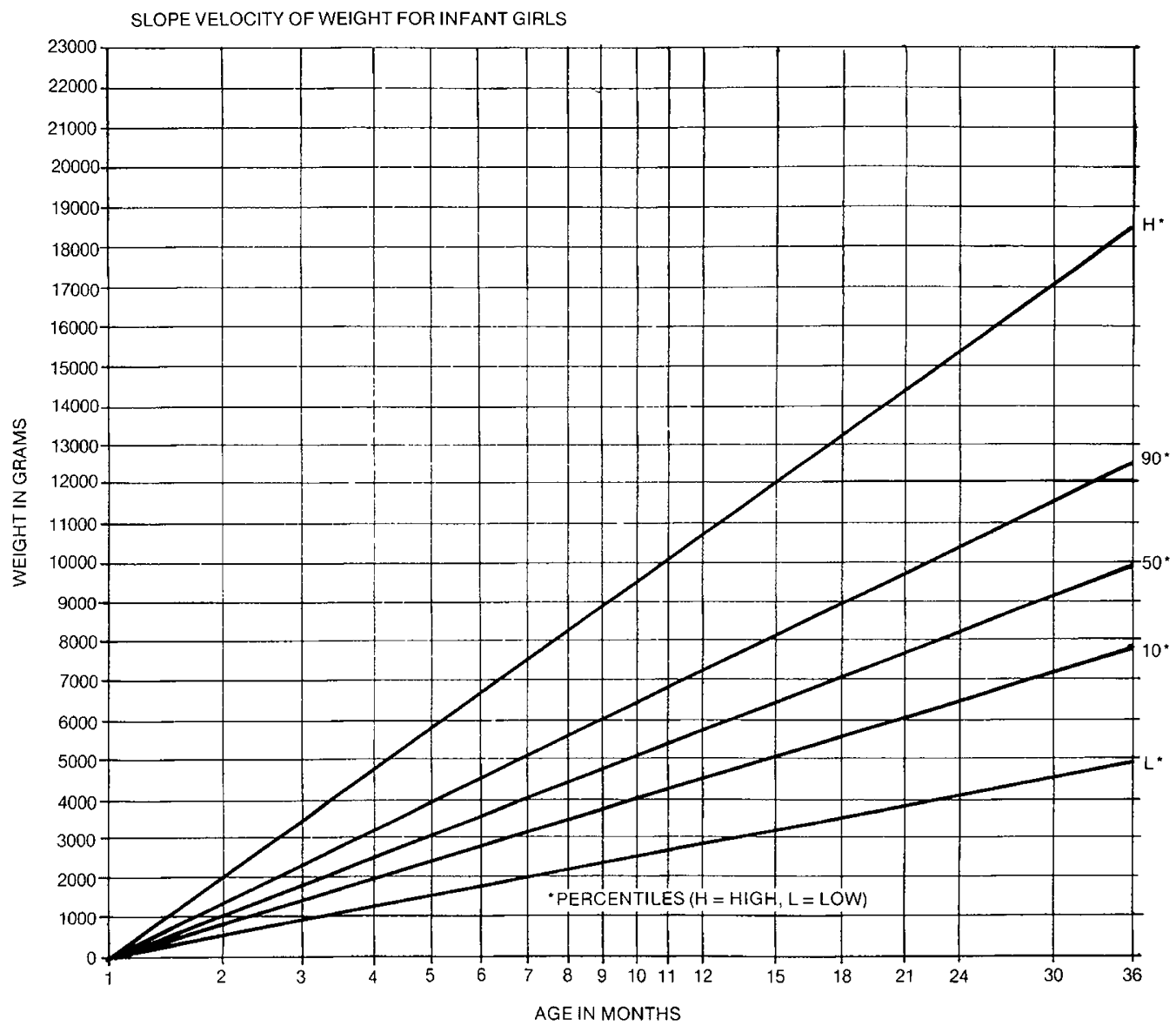

Fig. 5. Percentiles of slope velocity of weight for infant girls, from 1 to 36 months, including highest and lowest values of slope (compound logarithmic model). 


\section{SLOPE VELOCITY OF LENGTH FOR INFANT BOYS}

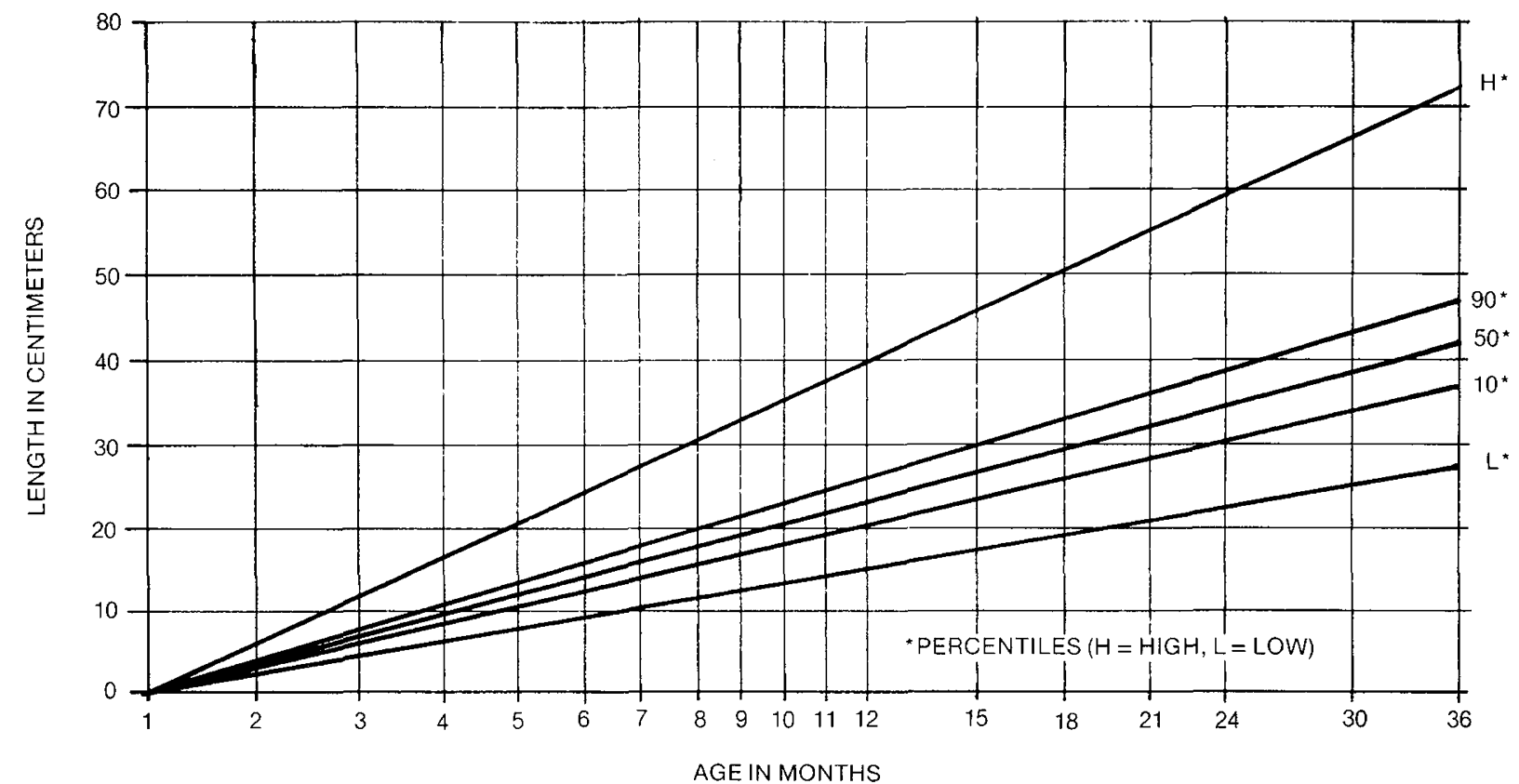

Fig. 6. Percentiles of slope velocity of length for infant boys, from 1 to 36 months, including highest and lowest values of slope (compound logarithmic model).

\section{SLOPE VELUCITY OF LENGTH FOR INFANT GIRLS}

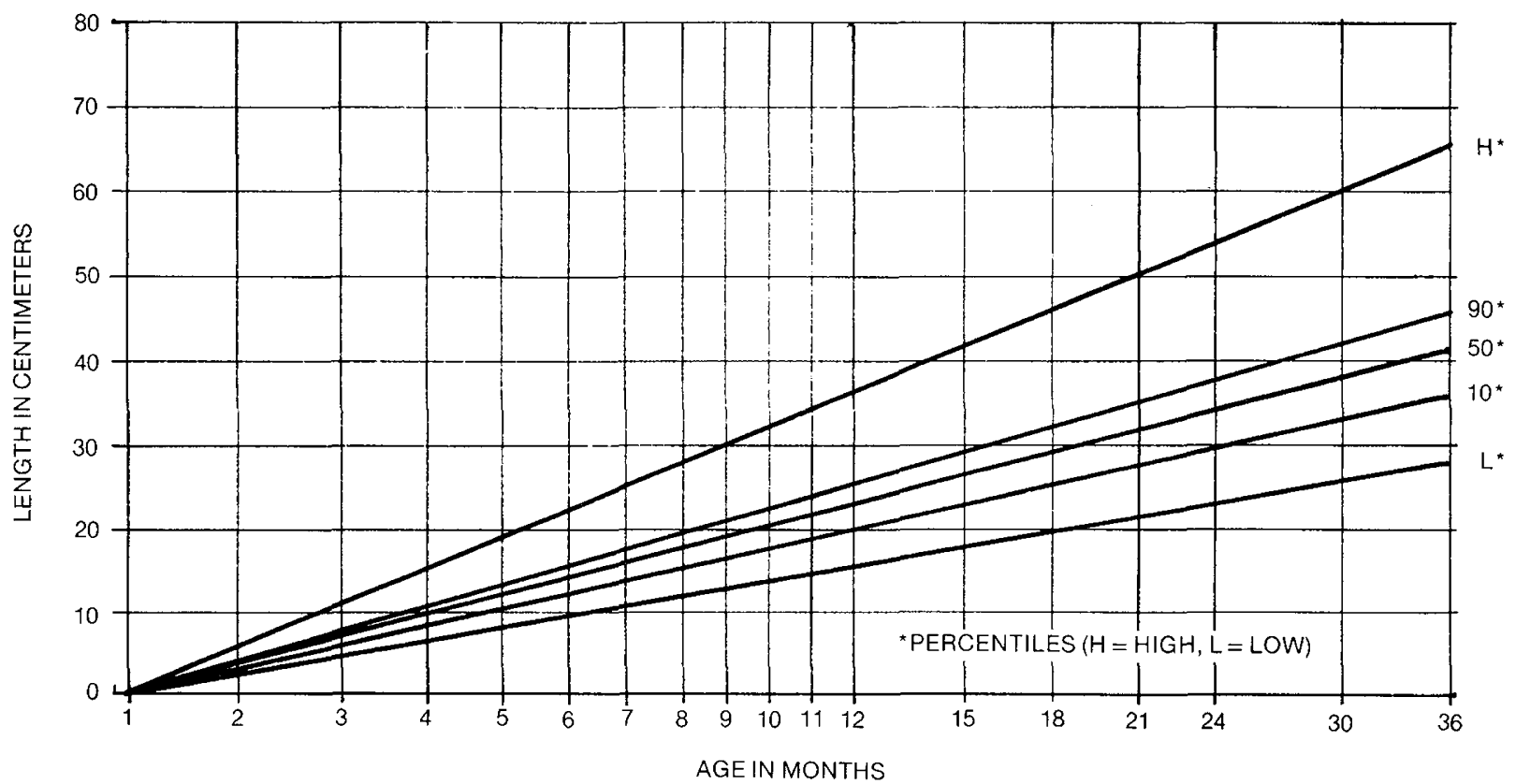

Fig. 7. Percentiles of slope velocity of length for infant girls, from 1 to 36 months, including highest and lowest values of slope (compound logarithmic model).

With these curves it was not necessary to compute separate scales for infant boys and for infant girls.

Each curve was then transposed to graph paper with a linear scale for $y$ and a special scale for $x$ so that the curve became a straight line. This transformation is analogous to the derivation of semilogarithmic paper, and is different for weight and for length. These new scales were used for plotting data from the same 50 random records previously sampled (3) in each of the four groups, i.e., weight and length for infant boys and weight and length for infant girls. "Goodness of fit" was tested by calculating the coefficient of determination $\left(\mathrm{r}^{2}\right)$ and by a runs test for ea' $\mathrm{h}$ record in the sample of 50 in each of the four categories. The runs test (2) analyzes the number of times that the actual data cross the least squares line.

\section{RESULTS}

Figure 1 is a typical graph for weight of an infant boy. We used both the least squares and graphic methods to demonstrate that the graphic (i.e., hand-drawn line) approach may be used without sacrificing correctness. Figure 2 assesses the curvilinearity of a plot of length of an infant boy which had previously had a poor straight line fit when the log scale for age was used. Although some curvilinearity persists, much flattening of the curve has been accomplished as indicated by the now insignificant runs test.

Table 1 summarizes the results of the runs tests and coefficients of determination for each of the four groups. In each group, $\mathrm{r}^{2}$ was $\geq 0.9$ in all of the 50 patients sampled. Numbers of significant runs tests at the 0.10 level declined appreciably from those found 
with the log-linear model. The model was better for length than for weight; in both cases, there were more "misfits" (significant runs tests) than would be expected by chance. Hence, the user must be very careful when applying this scale, especially for weights because individual variances in growth patterns are such that any observed deviation from our standards of velocity may be due to lack of fit rather than to true abnormal growth pattern.

Inasmuch as linear growth (length) is less susceptible to extraneous variables than is weight, the better fit of the log-linear model for length is understandable. Because length usually is more important in the assessment of growth patterns than is weight, the implications are much stronger if abnormal length velocity is seen.

These observations were further supported by Spearman rank correlations (1), comparing the rank order for the entire test population by the original log method versus the new scale. Table 2 indicates that the new scale produces results quite different from the previous scale for length (i.e., lower correlations) but somewhat similar for weights (i.e., higher correlations).

One of the major problems with the log-linear method was its tendency to understate velocity if only the early data was used. This effectively prevented its use for projections. Figure 3 uses the modified method to plot velocity lines for length of an infant girl. Some understatement in estimate of slope is present, but now it is only $25 \%$ instead of the $58 \%$ previously found with the log scale. Moreover, although the old scale always understated, the new scale may now either understate or overstate and hence is more accurate. Table 3 illustrates this for the four groups: the percentage differences in average slopes, all data versus data for 1 to 4 months, is approximately $\pm 5 \%$.

Although curvilinearity is thus much less by the new model and should decrease as extra data points are added, it remains suspect to project lines from early data only. As initially suggested (7), such projections should be pencil lines to permit correction if needed.

\section{APPLICATION}

Table 4 gives the percentiles of slopes of weight for infant boys and infant girls, incuding the highest and lowest. The numbers of observations and the accuracy of the results as indicated by the coefficients of determination $\left(\mathrm{r}^{2}\right)$ are included. Only 11 observations in males and 14 in females had $r^{2}$ below 0.90. In Table 5 are given the corresponding data for length for infant boys and infant girls. Only seven observations in males and seven in females had $\mathrm{r}^{2}$ below 0.90 .

Because of our initial impression that the physician or other health care professional will prefer a graphic method, the scale created for the new model was used to plot the slopes. The decision to plot these against a y-intercept of zero was again maintained. Figures 4 through 7 show the slopes of weights and of lengths for infant boys and girls. Selected percentiles are shown to enhance readability of the graphs.

\section{REFERENCES AND NOTES}

1. Colton, T.: Statistics in Medicine. pp. 223-224 (Little, Brown and Co., Boston, 1974).

2. Draper, N., and Smith, H.: Applied regression analysis. pp. 95-99 (John Wiley \& Sons, Inc., New York, 1967).

3. Krall, J. M., and Pomerance, H.H.: Analysis of errors in using linear regression to approximate growth curves. (Unpublished manuscript). Paper presented at Annual Meeting of the American Statistical Association, San Diego, CA, August, 1978.

4. Meredith, H. V.: A "Physical Growth Record" for use in elementary and high schools. Am. J. Public Health, 39: 878 (1949).

5. Mood, A. M., and Graybill, F. A.: Introduction to the theory of statistics. Ed. 2 pp. 344-348 (McGraw-Hill Book Co., New York, 1963).

6. National Center for Health Statistics: NCHS Growth Charts, 1976. Monthly Vital Statistics Report, Vol. 25, No. 3 (Suppl.), (Health Resources Administration, Rockville, MD, 1976).

7. Pomerance, H. H.: Growth standards in children. Chap. 15, pp. 197-214 (Harper \& Row, Publishers, Hagerstown, MD, 1979).

8. Tanner, J. M., Whitehouse, R. H., and Takaishi, M.: Standards from birth to maturity for height, weight, height velocity, and weight velocity: British children. Part I. Arch. Dis. Child., 4I: 454 (1966).

9. Tanner, J. M., Whitehouse, R. H., and Takaishi, M.: Standards from birth to maturity for height, weight, height velocity, and weight velocity: British children. Part II. Arch. Dis. Child., 41: 454 (1966).

10. Vickers, V. S., and Stuart, H. D.: Anthropometry in the pediatrician's office. J. Pediatr., 22: 155 (1943).

11. Wingerd, J.: The relation of growth from birth to 2 years to sex, parental size and other factors, using Rao's method of the transformed time scale. Hum. Biol., 42: 105 (1970).

12. Requests for reprints should be addressed to: Dr. H. H. Pomerance, Department of Pediatrics, West Virginia University Medical Center, 3110 MacCorkle Ave. SE, Charleston, WV 25304

13. Received for publication October $9,1980$.

14. Accepted for publication February 10, 1981. 